\title{
Hydroxyproline Measurement
}

National Cancer Institute

\section{Source}

National Cancer Institute. Hydroxyproline Measurement. NCI Thesaurus. Code C80190.

The determination of the amount of hydroxyproline present in a sample. 